the anacsthetic altogether. Owing to the synergic action of drugs a small quantity of anaesthetic produces very disproportionate effects. Open ether is safe, and the best anaesthetic. Very little is required (about one ounce) to make the child ready for the operation; the anaesthetic is taken without much struggle.

All children wake up whilst they are having cold douching after the operation, but though conscious they do not remember afterwards what has happened. They fall asleep as soon as they are put to bed. This sleep is prolonged and restful; it lasts between eight and sixteen hours; they wake up quite refreshed.

\section{Difficultifs and Dangers.}

Pre-operative Preparation.-It is possible that the preoperative preparation need not be so strict in the complete washing out of the rectum preliminary to the administration of the paraldehyde. Experience may prove castor oil, the night hefore, sufficient preparatory treatment; but, in view of tl. : fact that paraldehyde may act as an irritant of the rectum, and that a loaded colon would interfere with the absorption of the drugs, it was deemed advisable to have the pre-operative treatment as thorough as possible.

1)osage. - A dose of one drachm of paraldehyde per stone body weight was employed in the last 572 cases. In a first series of 82 cases only half a drachm per stone weight was used. This had definite disadvantages, for not only did it fail to induce satiffactory hypnosis, but it also seemed to act as an exciting agent. The sleep Induced light; the child was irritable, easily wakened, and would waken up when taken to the theatre. The administration of the anaesthetic would provoke a struggle, and after operation there wo:ld follow an exceedingly restless sleep lasting for four to six hours. With such a dose there seemed to be no effect on the pupils; respiration was unaffected, but blood pressure was raised. A dose of three-quarters of a drachm per stone weight was tried out in a second series of 146 cases. The results obtained were a great improvement on those obtained with the smaller dose. The sleep, though derper, was not sufficiently deep to prevent some of the children waking up when taken to the theatre. Struggling during the administration of anaesthesia was never very marked. The sleep after operation lasted for four to eight hours, but, as with the smaller dose, there was a distinct tendency towards restlessness. With this dosage the pupils tend to become contracted, and the blood pressure is raised. A dose of a drachm per stone body weight has no dangers, as shown by the last 572 cases, and has definite advantages. The sleep is deep; there is no restlessness before or after the operation, and hardly any struggling during the administration of the anaesthetic. With the full dose sleep lasts for eight to sixteen hours; the pupils are contracted; respiration is quiet; there is, however, a fall of blood pressure two or three hours after the operation.

Vehicle.-The paraldehyde should be dissolved in normal saline neither heated nor cooled, and this solution is to be run into the rectum. The solubility of paraldehyde is 1 in 10 at $0^{\circ} \mathrm{C}$.; it is less at higher temperatures, and over blood heat the paraldehyde tends to evaporate. Hutchison reports a case of considerable sloughing of the rectal mucosa owing to the administration of half an ounce of paraldehyde. But he injected it in a highly concentrated form (the pure drug) "along with three or four times its volume of water."

Difficulties in the Rectal Administration.-An unsuccessful rectal administration leads to the evacuation of the paraldehyde and failure of the attempted medication. Extreme slowness in the running in of the solution is an essential condition for success. Retention is further aided by strapping the nates together, in addition to putting a pad over the perineum. It is advisable to have a nurse who has had some experience in the administration of solutions per rectum.

Anaesthesia.-As already pointed out, the quantity of anaesthetic is small, and the preliminary medication ensures a maximum effect considering the amount of the anaesthetic employed. Open ether has been found safe; it has also the advantage of raising the blood pressure, thus counteracting the fall that the full dose of paraldehyde produces. Ethyl chloride is also safe, though a needlessly large dose may be administered should the child struggle. Chloroform would, however, seem to be highly dangerous. On one occasion, when ten children were being operated upon, all of them were given chloroform on top of the full dose of paraldehyde. In two cases there was severe collapse, the children turning greyish in colour; the pulse was rapid and thready, and the breathing was shallow. Chloroform has not been tried again. With ether the anaesthesia need be very light. The combined effect of the paraldehyde and ether, though producing complete narcosis and anaesthesia, is sufficiently light for the reflexes to persist. It is undesirable and unnecessary to push ether to the stage of abolishing the reflexes.

Complications.-In this series of 800 cases there were no complications that could be ascribed to the paraldehyde. In one case there was some slight bleeding after the operation. No active interference was necessary apart from swabbing out the throat. In another case the administration of the paraldehyde was unsuccessful. The child was unconscious on the table, was vomiting, and was difficult to anaesthetize. There was no apparent reason for this failure, though it is worth noting that this child was one of the earlier cases, and had not received the full dose of paraldehyde. Paraldehyde has an offensive odour: this seems to be more troublesome to the attendants than to the patients.

\section{Disadvantages.}

The advantages of preliminary medication are real enough; this is well illustrated by the attitude of the little patients. A child operated upon without prelininary medication fears and mistrusts the surgeon when he attempts to examine the throat after the operation; but children who have had paraldehyde show no such fear and mistrust. The majority readily open their mouths, and do not hinder the examination. Disadvantages, however, are none the less just as real and genuine. Preliminary medication implies considerable extra nursing, for not only are there extra duties before the operation, but more alertness is required from the nurse owing to the prolonged sleep of the children. There is also the disadvantage that the extra preparations throw some strain on the child: an enema, a wash-out, and rectal paraldehyde are rather trying to any patient. Finally, there is the disadvantage that the preparations imply in-patient treatment. While this is all for the good of the child, it cloes, unfortunately, present a serious problem at this time, when the accommodation for tonsillectomy cases is so woefully inadequate.

The observations recorded here were carried out at the Plaistow Children's Hospital and at the London Jewish Hospital. It is a pleasure to acknowledge $\mathrm{my}$ indebtedness to $\mathrm{Mr}$. W. $\mathrm{M}$. Mollison of Guy's Hospital for suggesting this work, and for his kindly interest and criticism.

\section{BIBLIOGRAPHY.}

Gwathmey, J. T. : Anaesthesia, second edition, London, 1925, pp. 438 and 704.

Rowbotham, E. S. : Preliminary Medication in Anaesthetics, Proc. Roy. ington, H. : Pre-medication by Paraldehyde in Children, ibid., 1929,

Phillips, H. R. : The Use of Paraldehyde before Anaesthesia, British Medical Journal, $1930, \mathrm{i}, 279$. Hutchison, R. : Ibid., 1930, in, 718.

\section{AMIDOPYRIN IN THE TREATMENT OF MEASLES.}

BY

G. W. RONALDSON, M.D., D.P.H., SENIOR ASSISTANT MEDICAL OFFICER, EASTERN HOSPITAL, L.C.C., AND

\section{J. I. COLlier, Ph.D., A.I.C., M.R.C.S.}

SrNce 1924, when Loewenthal ${ }^{1}$ published his paper on the value of amidopyrin in the treatment of measles, occasional short notes on this treatment have appeared in various foreign journals, but English writers have paid little attention to the use of this therapeutic agent. One of us (G. R.) tried the drug in a few cases of measles, but possibly on account of the fact that the cases were in a late stage of the disease the results did not appear sufficiently noteworthy to merit publication. In October, 1929, Hoyne of 
Chicago, ${ }^{2}$ who has been using this drug for a number of years, reported very favourably on its value in measles. In June of the present year, J. I. Collier ${ }^{3}$ recorded the results of its use in general practice during 1929, and since the appearance of his article several practitioners have contributed letters on the subject to the correspondence columns of the British Medical Journal. The consensus of opinion has been entirely in favour of the use of amidopyrin, and, indeed, some rather extravagant claims, based on the experience of a small number of cases, have been made for this method of treatment. In order to secure a more thorough test of the method, arrangements were made for the treatment to be carried out on a series of cases in hospital, where the facilities for observation and treatment are better than those existing in general practice. The present paper is a survey of the results in 150 cases treated during the past winter by the staff of the Eastern Hospital. At the outset an endeavour was made to secure early cases, our intention being to make a comparison with a corresponding number of untreated cases, but it was soon found that the number of patients admitted in an early stage of the disease was too small to allow of any satisfactory investigation. We therefore decided to treat as many patients as were available, and our series consists of unselected cases. The dosage adopted was 1 grain for each year of age, with a maximum of 5 grains. The drug was first given in the form of pyramidon crystals, but in the simultaneous treatment of a large number of patients, an aqueous solution containing 1 grain to the drachm was found to be more convenient, and less likely to give rise to nausea. Owing to its somewhat bitter taste, a few of our early patients who received the drug in powder form experienced slight rausea, but the liquid form was well tolerated, and no idiosyncrasy or any harmful effect was noted in any of the cases. The appropriate dose was administered four-hourly day and night until the temperature had settled. The treatment is comparatively cheap, the cost amounting to only a few pence per patient.

Results of Treatment.

The results of the treatment were very encouraging, but the type of measles prevalent in London during the winter 1529-30 was milder than usual, and we are therefore chary of making claims which further investigation might show to be inapplicable to a more severe type of the disease. The best results were achieved in the earlier cases, but even in the later stages the treatment appeared to benefit a certain number of patients. Our experience agreed with that of Hoyne in the respect that the tendency to bronchopneumonia was lessened and complications were fewer. Some patients who were already suffering from bronchopueumonia on admission to hospital did well, but the drug did not seem to exert any influence on measles laryngitis or measles enteritis. In view of these observations, we could not substantiate the claim that the drug exercises a "specific" action. In one instance "measles croup" developed in a patient whose treatment was initiated in the prodromal stage, and though this case made very satisfactory progress the occurrence of a serious early complication was unlooked for, despite a subsequent good result. From a reference by Hoyne to the " customary salicylates," one would gather that treatment by drugs, presumably administered for their antipyretic effect, is the usual practice in the treatment of measles in America. The efficacy of amidopyrin as an antipyretic is well recognized, and for this reason it is not surprising to find that Hoyne regards it as an advance on previous medicaments. Our own experience amply confirms this antipyretic effect, which was exhibited in almost every case.

In the majority of instances the temperature dropped to normal within twenty-four hours of the administration of the drug, and, though the precise therapeutic effect of a mere lowering of temperature may be a debatable point, a decided improvement in the patient's general condition accompanied the decline of the pyrexia. In a number of cases in which complications had supervened before treatment was initiated pyrexia continued, though on a lower level. Some writers have claimed that the use of amidopyrin in the prodromal stage will frequently exercise an abortive effect on the disease, and in one of our cases this effect certainly followed the giving of the drug; but we are well aware of the fact that a similar result in an untreated case would be by no means a phenomenal happening.

Our case was that of a boy who was admitted to hospital with pyrexia, coryza, and the usual appearance of a measles patient in the prodromal stage. Numerous Koplik's spots were visible, but he had no exanthem. Treatment was commenced on the afternoon of the day of admission, and next morning the boy was perfectly well. A few macules were then seen on the trunk, but no further symptoms appeared, and the rudimentary eruption only lasted for a few hours, during which time the patient appeared to be in excellent health. On the other hand, the case has already been referred to in which "measles croup" occurred in the prodromal stage of an attack for which treatment had already been commenced. The typical eruption appeared in this case, and was followed by quite marked staining. In many instances where the treatment was begun during the eruptive stage, the duration of the rash appeared to be shortened, but in other cases the eruption followed its usual course, even though there was considerable amelioration of the general condition. The treatment cannot therefore be said to have any constant effect on the measles exanthem. Two tables are appended, in which we have briefly summarized our results, our criteria for the allocation of cases to the different categories being severity of disease, duration of pyrexia and other symptoms, presence or absence of complications, and length of stay in hospital. Tho omission of statistics referring solely to complications will be noted, but we are of opinion that, as a number of our cases were of a comparatively benign type, the inclusion of these figures without the records of a parallel series of untreated cases would be unduly flattering to the treatment. In a subsequent communication, dealing with our experience of an extended series of cases, we hope to be able to furnish these and other details.

TABLF I.-Results according to Age Groups.

\begin{tabular}{|c|c|c|c|c|c|c|c|c|}
\hline \multicolumn{4}{|c|}{ Age in Years. } & $\begin{array}{c}\text { No. of } \\
\text { Cases } \\
\text { Treated. }\end{array}$ & $\begin{array}{c}\text { Good } \\
\text { Result. } \\
\text { A.* }^{*}\end{array}$ & $\begin{array}{c}\text { Good } \\
\text { Result. } \\
\text { B.t }\end{array}$ & $\underset{\substack{\text { No } \\
\text { Aprarent } \\
\text { Benefit. }}}{ }$ & Lied. \\
\hline \multicolumn{3}{|c|}{1 (and urder)... } & $\ldots$ & 34 & 15 & 6 & 10 & 3 \\
\hline $2 \ldots$ & $\ldots$ & ... & $\ldots$ & 27 & 12 & 8 & 6 & 1 \\
\hline $3 \ldots$ & ... & $\cdots$ & ... & 29 & 1) & 15 & 4 & 0 \\
\hline $4 \ldots$ & $\cdots$ & ... & .. & 34 & 14 & 18 & 2 & 0 \\
\hline $5 \ldots$ & $\ldots$ & $\ldots$ & $\ldots$ & 16 & 9 & 6 & 1 & 0 \\
\hline 6 to 9 & $\ldots$ & ... & ... & 10 & 5 & 3 & 2 & 0 \\
\hline & otal & $\ldots$ & ... & 150 & 65 & 55 & 25 & 4 \\
\hline
\end{tabular}

* Cases in which the good result was apparently attributable to

+ Cases in which a good result followed trfatment, but in which such factors as age, mildnes; of disease, etc, may have largely contrib such the favourable progress.

TABLE II.-Results according to Stage when Treatment was Initiated.

\begin{tabular}{|c|c|c|c|c|c|}
\hline Stage. & $\begin{array}{l}\text { No. of } \\
\text { Cases. }\end{array}$ & $\begin{array}{c}\text { Good } \\
\text { Result. } \\
\text { A. }\end{array}$ & $\begin{array}{c}\text { Good } \\
\text { Resuit. } \\
\text { B. }\end{array}$ & $\begin{array}{c}\text { No } \\
\text { Apnar: nt } \\
\text { Benefit. }\end{array}$ & Died. \\
\hline Prodromal $\quad \ldots \quad \ldots$ & 3 & 2 & 0 & 0 & 1 \\
\hline First day rash & 46 & 27 & 13 & 4 & 2 \\
\hline Second ," & 63 & 26 & 28 & 8 & 1 \\
\hline Third ". & 20 & 7 & 8 & 5 & 0 \\
\hline Fourth day and later & 18 & 3 & 7 & 8 & 0 \\
\hline Totals $\ldots . \ldots$ & 150 & 65 & 56 & 25 & 4 \\
\hline
\end{tabular}

The case of "measles c oup" already referred to is not included. The result was good, but sy mptoms of measles first developed during contrealmer.t.

The four deaths were due to broncho-pneumonia, and in each of the cases a coexisting enteritis was a contributory factor. Three of the cases were admitted on the same day 
from an institution in South-East London. These patients were in an early stage of measles, but enteritis was already present in all three instances. It is interesting to note that another case, previously admitted from the same institution, was also found to be suffering from enteritis, though no definite evidence of measles could be found in this patient. It is therefore possible that in this small group the enteritis was a precursor and not a complication of measles.

As might be experted, the best results were obtained in the earlier stages of the disease. In the later stages a few cases showed some very encouraging results, so that the treatment is not devoid of value even after some days have elapsed before the case comes under observation. Infants and very young subjects furnished the largest number of cases which derived no apparent benefit from treatment, and we have had under consideration the question of the advisability of increasing the dosage in these cases.

\section{Conclusions.}

1. Amidopyrin is a valuable adjuvant in the treatment of measles.

2. Its action is chiefly antipyretic, but it appears to exercise some influence on the other symptoms of the disease.

3 . Its value is greatest when given in the earlier stages, and in some instances it appears to modify the attack, but even in the later stages its use may be followed by good results.

4. From the results in our series of cases we are not yet in a position to give a definite pronouncement on the claim, made by certain writers, that the drug is a "specific" for measles.

5 . The treatment is comparatively inexpensive, and very simple in its method of administration. In the dosage used by us it seems to be devoid of deleterious effects.

6 . The use of amidopyrin merits further investigation over an extended series of cases.

\section{REFERENCES.}

${ }^{1}$ Loewenthal, M. : British Medical Jomrnal, 1924, ii, 51.

2 Hoyne, A. : Illinois Med. Journ., 1929, lvi, 254.

3 Collier, J. I. : British Medical Journal, 1930, i, 1093

\section{AMIDOPYRIN IN THE TREATMENT OF MEASLES.}

W. H. W. ATTLEE, M.D., M.R.C.P., MEMBER OF THE ETON COLLEGE MEDICAL BOARD.

The favourable reports in the British Medical Journal on the use of amidopyrin in measles decided me that it must be tried in an epidemic which happened to be going on at the time. It was a good opportunity for a test, seeing that all the patients were of one type and were nursed in similar circumstances. The epidemic, too, was half over, and the comparison between treated and untreated cases was made easv. This seems important, seeing that the severity of different epidemics varies within wide limits.

The patients were all boys at school, from $12 \frac{1}{2}$ to $16 \frac{1}{2}$ years of age. Each was nursed in a separate room with nurses who kept regular charts. The disease was of a mild type, and the weather was warm and sunny. Partly on this account probably, and partly because the general health was good, with an almost complete absence of catarrhal affections in the community, complications were few and convalescence was rapid. In all, 120 patients were treated on ordinary lines, and nine were given amidopyrin (pyramidon).

Cases Treated on Ordinary Lines.

The course of the disease in these 120 cases was similar in all during the prodromal stage. None felt particularly ill, and almost all wanted to eat light solids. The respiratory symptoms were slight in comparison with most epidemics. There was remarkably little cough and hoarseness. The temperature rose to its height as the eruption appeared, and then fell abruptly to normal, the whole period of real discomfort lasting, as a rule, only twentyfour hours. Most patients were able to get up in a week, and to go away for sick, leave in a fortnight after the rash appeared. In only four cases were there any marked signs of bronchial catarih. Many had transient redress of the tympanic membrane, often without any pain or other symptoms referred to the ear. Two had definite otitis, needing myringotomy on both sides. Both were healed within ten days.

In this group the severity of the disease varied within wide limits. One boy, for example, reported sick only because of the rash on his face. He never felt ill. The rash was scanty, the temperature was $100.4^{\circ} \mathrm{F}$. when he reported sick and was normal next day. At the opposite extreme was a boy who felt quite ill and reported sick four days before the rash appeared. Koplik's spots were present on the first day, three days before the rash. The rash and the injection of the palate were intense, and signs of broncho-pneumonia appeared two days after the eruption was at its height. Both tympanic membranes became congested, but resolved without myringotomy. The temperature was $104^{\circ}$ at its highest, and it did not settle to normal for thirteen days. The average total duration of the fever was 4.07 days, and the average greatest height was $103.5^{\circ}$.

\section{Cases Treated with Amidopyrin.}

These nine patients each received 5 grains every four hours, begining during the prodromal stage in three cases, and at the beginning of the eruption in six cases. The course of the disease was altogether different. The rash appeared more slowly, taking thirty-six to forty-eight hours to reach its height. The temperature rose as high as usual, but fell gradually and not abruptly, and the period of real discomfort was lengthened. This discomfort was increased in most cases by frequent vomiting. Complications were not prevented, for two patients had extensive bronchial catarrh and one of these had double otitis in addition, necessitating myringotomy on one side. Two had stomatitis and laryngitis so severe as to make feeding a trial and phonation impossible, complications unseen in the group treated on ordinary lines. The average total duration of the fever was 6.9 days, and the average greatest height was $103.5^{\circ}$

There could be no doubt that these nine cases were more uncomfortable and did less well than the others, and this fact was so obvious to both doctors and nurses that it seemed unjustifiable to continue the administration of amidopyrin.

Summary.

During a school epidemic of measles, nine patients were treated with amidopyrin and 120 on ordinary lines.

The patients treated with amidopyrin were more uncomfortable than the others, their rashes took longer to mature, their fever was more prolonged, and the percentage of complications was higher.

\section{TREATMENT OF VARICOSE ULCERS.*}

BY

A. DICKSON WRIGHT, M.S., F.R.C.S., ASSISTANT DIRECTOR, SURGICAL UNIT, ST. MARY'S HOSPITAL, LONDON.

By way of introduction I would stress some general considerations before proceeding to the details of treatment and the results to be expected. These are the prevalence of varicose ulcer, apathy of the medical profession with regard to it, the economic aspect, intractability of the disease, and its etiology.

The prevalence of varicose ulcer is not fully appreciated because a very large number of sufferers seldom see a doctor. The reason for this is that both patient and doctor grow tired of ineffectual treatment and avoid each other. The patient either uses well-advertised remedies or is dealt with by the out-patient or district nurse. The cases will come out of hiding in large numbers if they are encouraged; as witness of this, I have treated and cured upwards of three hundred cases of indolent leg ulcer during the last two years.

* A paper read at a meeting of the Section of Surgery at the Annual Meeting of the British Medical Association, Winniper, 1930 . 